\title{
METHOD FOR VOLTAGE CONTROL IN CHARGE CIRCUIT OF ELECTRIC DISCHARGE INSTALLATIONS WITH TWO CAPACITORS UNDER NONZERO INITIAL CONDITIONS
}

Purpose. To analyze the transient processes in the charge circuit of electric discharge installations with two capacitors, taking into account the change in the initial conditions of such processes (initial voltage on the capacitors and the initial current in the charge circuit) as well as to develop the method for charge voltage control of such installations using purposeful change of these initial conditions. Methodology. We have applied the concepts of theoretical electrical engineering, the principles of theory of electrical circuits, and mathematical simulation in the software package MathCAD 12. Results. We have obtained analytical expressions and graphical dependencies establishing a quantitative relationship between the value of the maximum charge voltage of an electric discharge installation and the values of the initial voltage on its capacitors and the initial current in the circuit. This allows us to propose the method for the charge voltage control of electric discharge installations with two reservoir capacitors, using a purposeful change in their initial voltages and initial current in the charge circuit. Originality. For the first time, we have found that the charge voltage of the installation can be controlled using two influence mechanisms - either changing the initial current in the charge circuit (by interrupting the transient process of the first capacitor charge at a certain time) or using a nonzero initial voltage on the charged second capacitor. In this case the charge voltage can be varied by 2 times. Practical value. The use of this method makes it possible to obtain discharge pulses of complex shape in the technological load, since the maximum charge voltages of the first capacitor and second one can differ by a factor of 1.5 . References 10, figures 4.

Keywords: electric discharge installation, capacitor charge, charge voltage, transients, nonzero initial conditions.

Цель. Целью статьи является анализ переходных процессов в зарядной цепи электроразрядных установок с двумя конденсаторами с учетом изменения начальных условий протекания таких процессов (начального напряжения на конденсаторах и начального тока в зарядной цепи), а также разработка метода регулирования зарядного напряжения таких установок, используя целенаправленное изменение указанных начальных условий. Методика. Для проведения исследований использовались положения теоретической электротехники, теория электрических цепей, математическое моделирование в программном пакете МатһCAD 12. Результаты. Получены аналитические выражения и графические зависимости, устанавливающие количественную связь между значением максимального зарядного напряжения установок и величинами начального напряжения на ее конденсаторах и начального тока в цепи. Предложен метод регулирования напряжения заряда электроразрядных установок с двумя накопительными конденсаторами, использующий целенаправленное изменение их начальных напряжений и начального тока в зарядной цепи. Научная новизна. Установлено, что напряжение заряда установки можсно регулировать, используя два механизма влияния - как изменяя начальный ток в зарядной цепи (прерыванием переходного процесса заряда первого конденсатора в определенный момент времени), так и используя ненулевое начальное напряжение на заряжаемом втором конденсаторе. При этом напряжение заряда можно изменять в 2 раза. Практическое значение. Использование данного метода позволяет получить разрядные импульсы сложной формы в технологической нагрузке, поскольку максимальные напряжения заряда первого и второго конденсаторов могут отличаться в 1,5 раза. Библ. 10, рис. 4.

Ключевые слова: электроразрядная установка, заряд конденсатора, зарядное напряжение, переходные процессы, ненулевые начальные условия.

Introduction. Electric discharge installations (EDIs) with capacitive energy storage devices (reservoir capacitors) have found wide application in the development of new technologies for electric pulse treatment of materials and media (in particular, electro-erosion, electrohydraulic, magneto-pulse treatments, etc.) [1-8].

The use of parallel connection of capacitors with different capacities is one of the most common methods for control of the EDIs dynamic parameters.

So, for example, several capacitors with different capacities, which are discharged through a load with a time delay, are used in many schemes of electric discharge installations in order to control the shape of the pulse currents in the load $[1,2,9]$. In the installations containing semiconductor DC voltage shapers with filtering capacitors of high-capacity, additional dosing capacitors are used to more accurately control the energy in the load $[1,7,8,10]$. Additional low-capacity dosing capacitors are also used in the input circuits of semiconductor converters to stabilize the power consumed by them from the electrical network $[2,3,5,10]$.

It should be noted that in most of considered electric discharge installations, the initial charge voltages and the final discharge voltages of their capacitors were equal to zero [1, 3-6].

At the same time, the reservoir capacitor is not completely discharged in the EDIs for volumetric electrospark dispersion (VESD) of metal granules in a dielectric liquid. The residual voltage of the capacitor is used as information for changing the voltage of the subsequent charge of the capacitor [7]. In these installations, the dependence of the resistance of the electric spark load on the magnitude and duration of the discharge current is used for parametric stabilization of the dispersion modes [7, 8].

If an oscillatory discharge of the capacitor through the load occurs and the capacitor is partially recharged to a reverse polarity voltage, then the negative feedback

(C) N.I. Suprunovska, M.A. Shcherba 
of the subsequent charge voltage of the capacitor with its previous discharge voltage is realized in the installation. If an aperiodic discharge occurs, then a positive feedback between these voltages is realized. In fact, high-speed control and parametric stabilization of electrical technological modes is implemented in such installations [7, 8].

Thus, the change in the magnitude and sign of the initial voltage of the capacitor can be used to develop methods for high-speed control of energy in the capacitor, discharge pulse parameters, EDIs efficiency, as well as for parametric stabilization of discharge processes in a circuit with a nonlinear load $[7,8]$.

The solution of the problems of improving the energy characteristics of such EDIs is much more complicated when you change the initial and final conditions of the transients in circuits of reservoir capacitors that are part of such installations.

In addition, the analysis of transient processes with a nonzero initial current in the charging circuit of the EDIs with several reservoir capacitors has not been carried out previously.

Therefore, the purpose of this paper is to analyze the transient processes in the charge circuit of electric discharge installations for the VESD with two reservoir capacitors, taking into account the change in the initial conditions of such processes (initial capacitors voltage and the initial current in the charge circuit), as well as to develop the method for control of the charge voltage of such installations using purposeful change of these initial conditions.

As a typical example of such EDIs, we have considered the installation for electro-spark dispersion of conductive granules in a dielectric liquid, the charge circuit of which includes two reservoir capacitors.

Features of the capacitor charge when the initial current changes. The electric schematic diagram of the charge circuit of the EDI, where the transient processes are analyzed, is shown in Fig. 1.

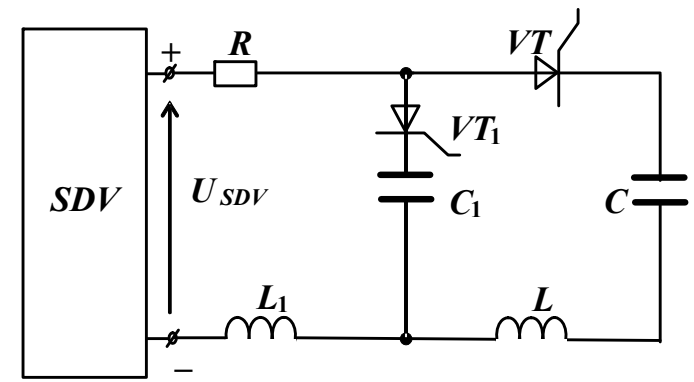

Fig.1. Electric schematic diagram of the charge circuit of EDI with two reservoir capacitors

The capacitor $C$ (Fig. 1) is charged from a shaper of direct voltage $(S D V)$ with an output voltage $U_{S D V}$ through a resistor $R$, thyristor commutator $V T$, and inductance coils $L$ and $L_{1}$. The thyristor $V T_{1}$ was locked up to a certain time $t=t_{1}$. There is an oscillatory charge of capacitor $C$ in the charge circuit, since the parameters of the circuit elements $\left(R, C, L, L_{1}\right)$ were chosen in such a way as to realize high Q-factor of the circuit $(Q \geq 10)$.

At time $t=t_{1}$, when the charge voltage of the capacitor $C$ becomes higher than the $S D V$ voltage $U_{C}>U_{S D V}$, the thyristor commutator $V T_{1}$ is unlocked.
The capacitor $C_{1}$ begins to charge from the $S D V$. We assume that in the general case there is some voltage on the capacitor $C_{1}\left(U_{0 C_{1}} \neq 0\right)$ before starting its charge.

Since $U_{C}>U_{S D V}$, then the capacitor $C$ tries to discharge to the capacitor $C_{1}$, however, the occurrence of reverse current in the circuit leads to the locking of the thyristor $V T$. Inductance $L$ is needed to limit the reverse current in the circuit when the thyristor $V T$ is locked.

Thus, there are two transient processes in the charge circuit of an EDI with two capacitors: the first process is the charge of the capacitor $C$ from the $S D V$ in the time interval $0 \leq t \leq t_{1}$ and the second process is the charge of the capacitor $C_{1}$ from the $S D V$ at $t>t_{1}$.

In the analysis of transient processes we have assumed that the thyristors $V T$ and $V T_{1}$ are ideal switches (without energy losses and with instantaneous commutation), and the inductance value $L$ is less by two orders of the inductance $L_{1}$, therefore, value $L$ can be ignored in the analysis of the first transient process.

Since the first transient is the ordinary oscillating charge of the capacitor $C$ from the $S D V$ under zero initial conditions, then we have analyzed in detail only the second transient process - the charge of the capacitor $C_{1}$ from the $S D V$, which occurs under a nonzero initial conditions in voltage $U_{0 C_{1}}$ and in current $I_{1}$ (due to the first transient process and the presence of inductance in the circuit) after switching thyristor $V T_{1}$.

The initial current $I_{1}$ is determined by the known formulas for the oscillatory charge of the capacitor from a direct voltage source. The parameters of the charge circuit of the capacitor $C_{1}\left(R, C_{1}, L_{1}\right)$ are also chosen so there was an oscillatory transient process.

Transient analysis of the capacitor charge under nonzero initial voltage and current conditions. The initial time of the second transient process is $t=t_{1}$ and we denote it as $t_{0}^{*}$. The current time of this transient process, denoted by $t^{*}$, is defined as $t^{*}=t-t_{1}=t-t_{0}^{*}$.

According to the second Kirchhoff's law the current in the $S D V-R-V T_{1}-C_{1}-L_{1}-S D V$ circuit (Fig. 1) is given by formula

$$
i\left(t^{*}\right)=\left(U_{S D V}-u_{C_{1}}\left(t^{*}\right)-u_{L_{1}}\left(t^{*}\right)\right) / R,
$$

here $u_{C_{1}}\left(t^{*}\right)$ and $u_{L_{1}}\left(t^{*}\right)$ are the voltage drop across the capacitor $C_{1}$ and the inductance $L_{1}$, respectively.

$$
\begin{array}{cr}
\text { Since } \quad i\left(t^{*}\right)=C_{1} d u_{C_{1}}\left(t^{*}\right) / d t^{*}, & \text { and } \\
u_{L_{1}}\left(t^{*}\right)=L_{1} d i\left(t^{*}\right) / d t^{*}=L_{1} C_{1} d^{2} u_{C_{1}}\left(t^{*}\right) / d t^{* 2}, & \text { then }
\end{array}
$$
equation (1) can be reduced to the form:

$$
\frac{d^{2} u_{C_{1}}\left(t^{*}\right)}{d t^{* 2}}+\frac{R}{L_{1}} \frac{d u_{C_{1}}\left(t^{*}\right)}{d t^{*}}+\frac{d u_{C_{1}}\left(t^{*}\right)}{L_{1} C_{1}}=\frac{U_{S D V}}{L_{1} C_{1}}
$$

Taking into account that in the general case there are the certain voltage $U_{0 C_{1}} \neq 0$ on the capacitor $C_{1}$ before start of its charge and nonzero current of value $I_{1}$ in the circuit (determined in the first transient process of charging the capacitor $C$ ), then we can write the solution of such a non-uniform equation in the form: 


$$
\begin{aligned}
& u_{C_{1}}\left(t^{*}\right)=U_{S D V}+\left[\left\{p_{2}\left(U_{0 C_{1}}-U_{S D V}\right) /\left(p_{2}-p_{1}\right)-\right.\right. \\
& \left.\left.-I_{1} / C_{1}\right\} e^{p_{1} t^{*}}+\left\{I_{1} / C_{1}-p_{2}\left(U_{0 C_{1}}-U_{S D V}\right)\right\} e^{p_{2} t^{*}}\right] .
\end{aligned}
$$

Since $i\left(t^{*}\right)=C_{1} d u_{C_{1}}\left(t^{*}\right) / d t^{*}$, the expression for the current in the charge circuit can be written as:

$$
\begin{aligned}
i\left(t^{*}\right)= & \left(U_{0 C_{1}}-U_{S D V}\right)\left(e^{p_{1} t^{*}}-e^{p_{2} t^{*}}\right) / L_{1}\left(p_{2}-p_{1}\right)+ \\
& +I_{1}\left(p_{2} e^{p_{2} t^{*}}-p_{1} e^{p_{1} t^{*}}\right) /\left(p_{2}-p_{1}\right) .
\end{aligned}
$$

Since charge circuit parameters are selected so that the circuit has a high $Q$-factor, then there is an oscillatory transient process, and consequently the roots of the characteristic equation are conjugate complexes:

$$
\begin{aligned}
& p_{1}=-R / 2 L_{1}+j \sqrt{1 / L_{1} C_{1}-R^{2} / 4 L_{1}^{2}}=-b+j \omega, \\
& p_{2}=-R / 2 L_{1}-j \sqrt{1 / L_{1} C_{1}-R^{2} / 4 L_{1}^{2}}=-b-j \omega,
\end{aligned}
$$

here $\omega=\sqrt{1 / L_{1} C_{1}-R^{2} / 4 L_{1}^{2}}, \quad b=R / 2 L_{1}$.

After substituting the values of $p_{1}$ and $p_{2}$ in (3) and (4) and performing the transformations, we obtain expressions for $u_{C_{1}}\left(t^{*}\right)$ and $i\left(t^{*}\right)$ :

$$
\begin{aligned}
u_{C_{1}}\left(t^{*}\right)= & U_{S D V}-\chi e^{-b t^{*}}\left(\left(b / \omega-I_{1} / \omega \cdot \chi \cdot C_{1}\right) \sin \omega t^{*}+\right. \\
& \left.+\cos \omega t^{*}\right) \\
i\left(t^{*}\right)= & e^{-b t^{*}}\left[\left(\chi / L_{1} \omega-I_{1} b / \omega\right) \sin \omega t^{*}+I_{1} \cos \omega t^{*}\right],
\end{aligned}
$$

here $\chi=U_{S D V}-U_{0 C_{1}}$.

The value of the current $I_{1}$, which is the initial current for second transient (charge transient of the capacitor $C_{1}$ ), we determine by the formula for the oscillatory charge of the capacitor $C$ (in general having some initial voltage $\left.U_{O C}\right)$ from the $S D V$ :

$$
I_{1}=i\left(t=t_{1}\right)=\left(U_{S D V}-U_{0 C}\right) e^{-b t_{1}} \cdot \sin \omega_{1} t_{1} / L_{1} \omega_{1},
$$

here $\omega_{1}=\sqrt{1 / L_{1} C-R^{2} / 4 L_{1}^{2}}$.

Calculations and data processing for the charge circuit (Fig. 1) with parameters $U_{S D V}=500 \mathrm{~V}, L=2 \cdot 10^{-6} \mathrm{H}$, $L_{1}=2 \cdot 10^{-4} \mathrm{H}, C=10^{-4} \mathrm{~F}, C_{1}=4 \cdot 10^{-5} \mathrm{~F}, R=0.1 \mathrm{Ohm}$ we have performed using the software package MathCAD 12. As mentioned above, the inductance $L$ is two orders of magnitude smaller than $L_{1}$, so we did not take it into account when performing calculations.

Table 1 shows the results of the calculation of the first transient process (the currents in the charge circuit and the charge voltage of capacitor $C$ in the time interval from $t \approx \tau_{\text {charge }} / 2$ (when the current is $I_{1}=I_{1 \max }$ ) to $t=\tau_{\text {charge }}\left(\right.$ when current $I_{1}=0$ ). Here $\tau_{\text {charge }}$ is the charge duration of capacitor $C$. These results are required for further analysis.

Analysis of the results of Table 1 shows that interrupting the charging process of capacitor $C$, when the charge circuit current reaches values in the range $I_{1 \max } \div 0$, we can change the control conditions of the charge voltage of the capacitor $C$, i.e. we can adjust the charge voltage (to perform so-called a tune-up) in the range of $7 \div 50 \%$.

Fig. 2 represents the time dependence of the current in the charge circuit of the EDI $i\left(t^{*}\right)$ for various values of the initial current $I_{1}:\left(0, I_{1 \max } / 2,2 I_{1 \max } / 3, I_{1 \max }\right)$ and the initial voltage $U_{0 C_{1}}=0$.

Table 1

The results of calculation of currents and charge voltages of capacitor $C$ in the time interval from $t \approx \tau_{\text {charge }} / 2$ to $t=\tau_{\text {charge }}$

\begin{tabular}{|c|c|c|}
\hline$t_{1} \cdot 10^{-6}, \mathrm{~s}$ & $i\left(t_{1}\right), \mathrm{A}$ & $u\left(t_{1}\right)=U_{C \max }, \mathrm{V}$ \\
\hline 217.9 & $I_{1}=I_{1_{\max }}=335$ & 469 \\
\hline 337.9 & $I_{1}=2 I_{1_{\max }} / 3=223$ & 824 \\
\hline 366.9 & $I_{1}=I_{1 \max } / 2=168$ & 881 \\
\hline 444.4 & $I_{1}=0$ & 947 \\
\hline
\end{tabular}

$i\left(t^{*}\right), \mathrm{A}$ for $U_{0 C 1}=0$

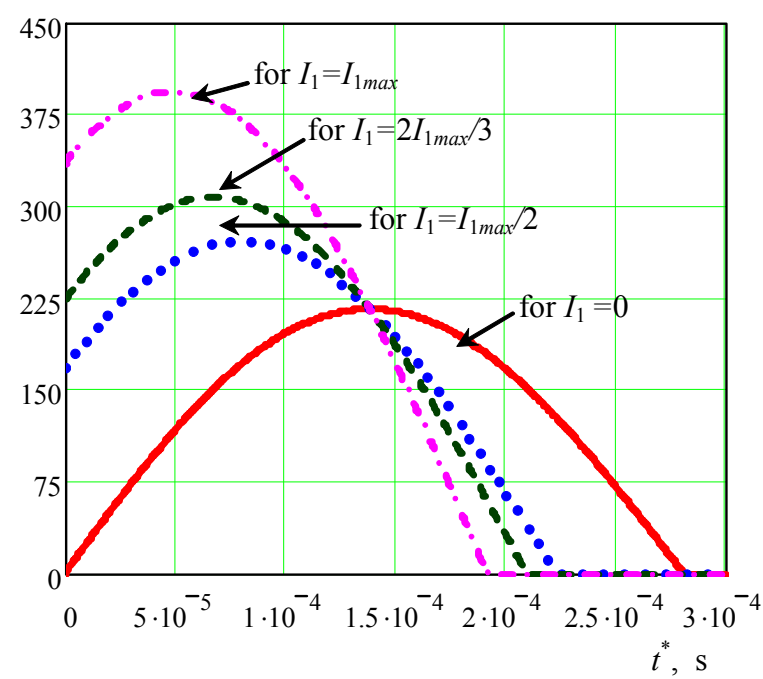

Fig. 2. The time variation in the charging current of capacitor $C_{1}$ with initial voltage $U_{0 C 1}=0$ at different initial circuit current values

As can be seen from Fig. 2, with a decrease in the value of the initial current $I_{1}$ the amplitude value of the current in the charge transient process of the capacitor $C_{1}$ decreases, and the duration of current flow increases. In other words, the earlier the first transient is interrupted, the faster and with the higher currents the second one proceeds.

Fig. 3, $a-c$ shows the time dependence of the voltage $u_{C_{1}}\left(t^{*}\right)$, and Table 2 represents the values of the maximum charge voltage of the capacitor $C_{1}$ for different initial current $I_{1}\left(0, I_{1 \max } / 2,2 I_{1 \max } / 3, I_{1 \max }\right)$ and initial voltage $U_{0 C_{1}}\left(0, U_{S D V} / 2,2 U_{S D V} / 3\right)$.

Analyzing dependences shown in Fig. 3 and the data in Table 2, we can conclude that with a decrease in the initial current $I_{1}$, the maximum charging voltage of the capacitor $C_{1}$ in the second transient process also decreases.

So if the initial current decreases from $I_{1 \max }$ to zero, the voltage value $U_{C_{1} \max }$ decreases by $30 \%$ at $U_{0 C_{1}}=0$ and by $47 \%$ at $U_{0 C_{1}}=2 U_{S D V} / 3$. Thus, the magnitude of the initial voltage $U_{0 C_{1}}$ also affects the value of $U_{C_{1} \max }$, and with increasing $U_{0 C_{1}}$ the voltage $U_{C_{1} \max }$ also decreases. 
For example, if the initial voltage $U_{0 C_{1}}$ of the capacitor $C_{1}$ increases from zero to $2 U_{S D V} / 3$ when the value of the current in the $S D V-R-V T-C-L-L_{1}-S D V$ circuit $I_{1}=I_{1 \max }$, the value of the maximum charge voltage $U_{C_{1} \max }$ of the capacitor $C_{1}$ decreases by $9 \%$, and at current value $I_{1}=0$ this voltage decreases by $32 \%$. In other words, the later the first charge transient of capacitor $C$ is interrupted, and the higher initial voltage on capacitor $C_{1}$, the lower its maximum charge voltage after second transient.
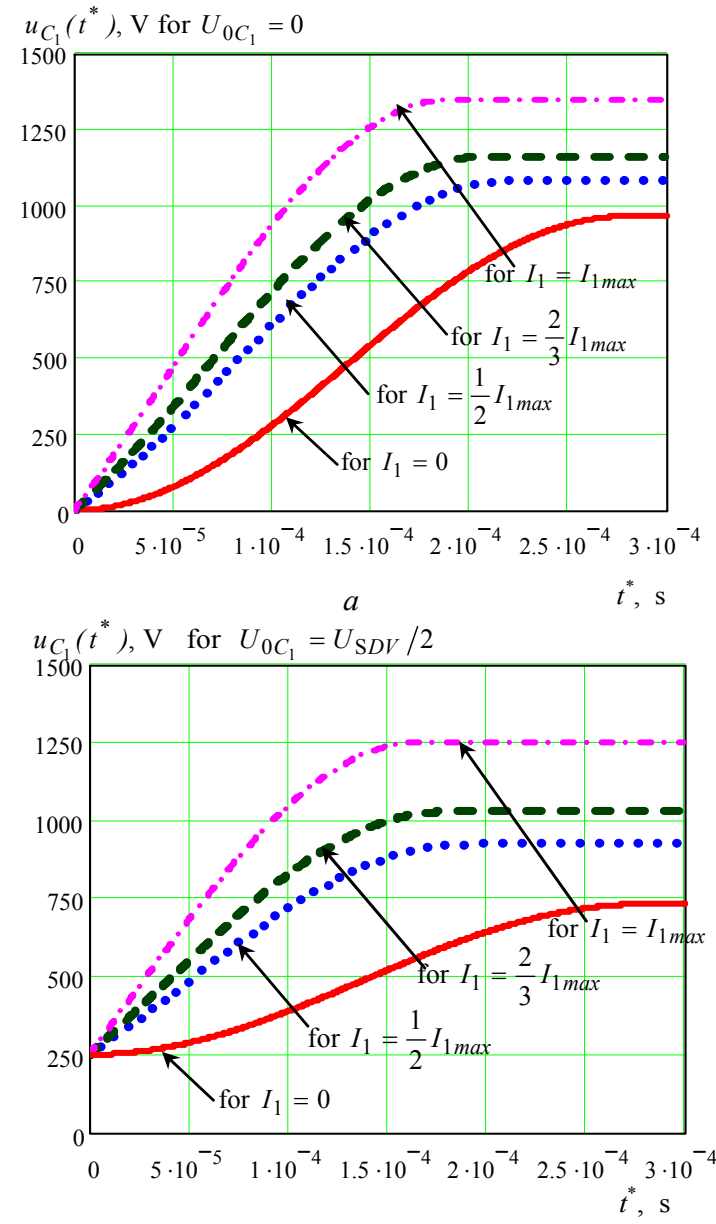

$b$

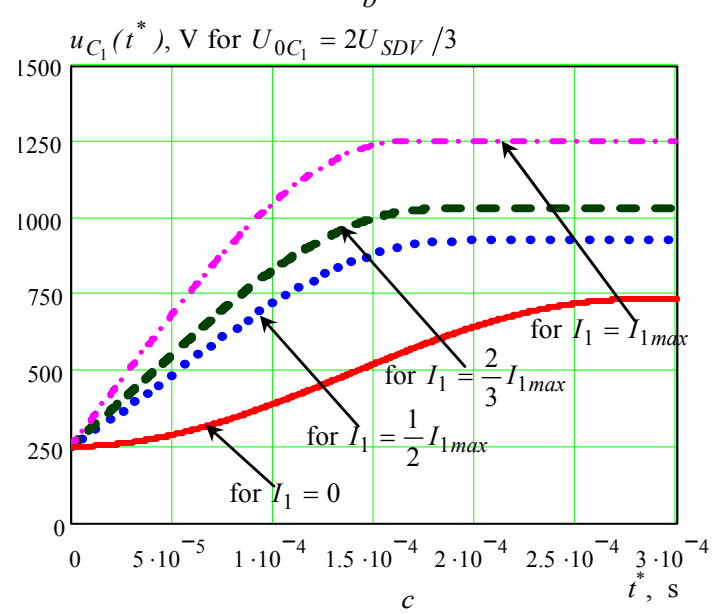

Fig. 3. The change with time of the charge voltage $u_{C 1}\left(t^{*}\right)$ of the capacitor $C_{1}$ at its various initial voltages and different initial values of the current in the circuit $\left(0, I_{1 \max } / 2,2 I_{1 \max } / 3, I_{1 \max }\right)$ : $a-$ for $U_{0 C 1}=0 ; \quad b-$ for $U_{0 C 1}=U_{S D V} / 2 ; \quad c-U_{0 C 1}=2 U_{S D V} / 3$
Fig. 4 represents the dependence of maximum voltage $U_{C_{1} \max }$ on the initial current $I_{1}$ for different initial voltages $U_{0 C_{1}}$ on the capacitor $C_{1}$.

Table 2

Maximum charge voltage $U_{C_{1} \max }$ for different values $I_{1}$ and $U_{0 C_{1}}$

\begin{tabular}{|l|c|c|c|}
\hline$I_{1}, \mathrm{~A}$ & 0 & $U_{S D V} / 2$ & $2 U_{S D V} / 3$ \\
\hline$I_{1}=I_{1 \max }$ & 1349 & 1252 & 1234 \\
\hline$I_{1}=2 I_{1 \max } / 3$ & 1163 & 1029 & 1001 \\
\hline$I_{1}=I_{1 \max } / 2$ & 1084 & 925 & 889 \\
\hline$I_{1}=0$ & 966 & 733 & 655 \\
\hline
\end{tabular}

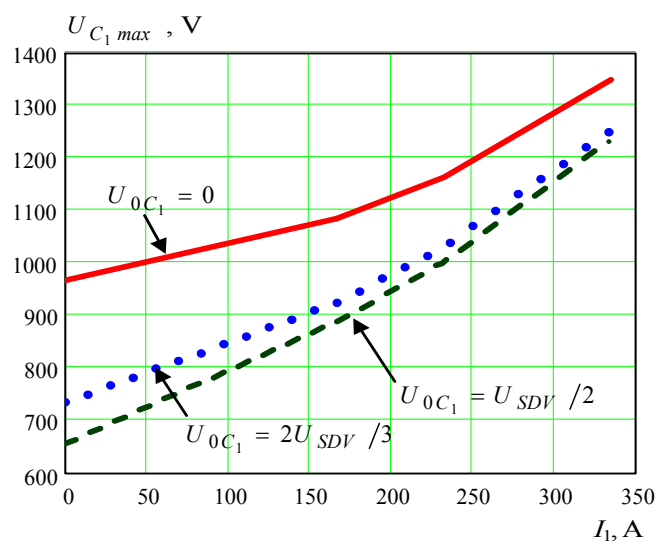

Fig. 4. The change in the maximum charge voltage $U_{C_{1} \max }$ of

the capacitor $C_{1}$ as a function of the magnitude of the initial current $I_{1}$, at which the transient of charge $C_{1}$ begins

As can be seen in Fig. 4, the charge voltage of the capacitor $C_{1}$ can be controlled by changing the initial current in its charge circuit by means of varying the duration of the charge process of the capacitor $C$.

The charge voltage of the capacitor $C_{1}$ can also be adjusted by changing its initial voltage before the start of the charge process. Of course, we can simultaneously use both methods for control of voltage $U_{C_{1}}$ max . In this case, the control range can be $655 \div 1349 \mathrm{~V}$, that is, the charge voltage can be changed by 2 times.

The charge voltage of the capacitor $C_{1}$ can be almost 1.5 times higher than the charge voltage of the capacitor $C$ (see Tables 1 and 2). This fact can be used to produce discharge pulses of complex shapes in spark load.

\section{Conclusions.}

1. We have carried out the transient analysis in the charge circuit of the capacitors of electric discharge installation, taking into account the change in the initial conditions of such transients (initial voltage on the capacitors and the initial current in the charging circuit). As the results we have defined the analytical expressions for determining the current in the circuit and the capacitor voltage during its charge under nonzero initial current and voltage conditions.

2. From the formula for the capacitor charge voltage under nonzero initial conditions in such installations follows that it depends on two factors: the initial voltage of this capacitor and the value of the initial current in this transient process. The numerical experiment of capacitor charge under nonzero initial conditions has shown that the 
maximum capacitor voltage decreases both with increasing its initial voltage and with decreasing initial circuit current.

3. Based on the revealed dependencies, we proposed a method for charge voltage control of such installations by changing the initial current in the charge circuit (by interrupting the first transient at a certain time), and by using a nonzero initial voltage on the second charged capacitor. The difference in capacitors voltage of the installation can be used to produce discharge pulses of complex shape in the technological load.

\section{REFERENCES}

1. Vovchenko A.I., Tertilov R.V. Synthesis of capacitive nonlinear- parametrical energy sources for discharge and pulse technologies. Proceedings of the National University of Shipbuilding, 2010, no.4, pp. 118-124. (Rus).

2. Onishchenko L., Gunko V., Grebennikov I., Bandura A Capacitors for various electrophysical and technological pulsed power applications. Proceedings of the 1st Intl Congress on Radiation Physics, High Current Electronics, and Modification of Materials. Tomsk, HCEI, 2000, vol.2, pp. 366-367.

3. Casanueva R., Azcondo F.J., Branas C., Bracho S. Analysis, Design and Experimental Results of a High-Frequency Power Supply for Spark Erosion. IEEE Transactions on Power Electronics, 2005, vol.20, no.2, pp. 361-369. doi: 10.1109/tpel.2004.842992.

4. Ivanov A.V., Sinchuk A.V., Ruban A.S. Effect of the technological parameters of the melt treatment by a electric pulse current on the mixing process. Surface Engineering and Applied Electrochemistry, 2012, vol.48, no.2, pp. 180-186. doi: $10.3103 / \mathbf{s} 106837551202007 x$.

5. Sen B., Kiyawat N., Singh P.K., Mitra S., Ye J.H., Purkait P. Developments in electric power supply configurations for electrical-discharge-machining (EDM). The Fifth International Conference on Power Electronics and Drive Systems PEDS 2003. Singapore, 17-20 November 2003, vol.1, pp. 659-664. doi: 10.1109/PEDS.2003.1282955.
6. Sunka P., Fuciman M., Babicky V., Clupek M., Benes J., Pouckova P., Soucek J. Generation of focused shock waves by multi-channel electrical discharges in water. Conference Record of the Twenty-Fifth IEEE International Power Modulator Symposium, Hollywood, California, USA, 2002, pp. 174-177. doi: 10.1109/MODSYM.2002.1189444.

7. Suprunovska N.I. Analysis of interdependent chargedischarge processes of capacitor in circuits with positive voltage feedback. Technical electrodynamics, 2017, no.4, pp. 14-21. (Rus). doi: 10.15407/techned2017.04.014.

8. Shcherba A.A., Suprunovska N.I. Cyclic transients in the circuits of electric discharge installations taking into account the influence of magnitude and rate of discharge currents rise on resistance of electric spark load. Technical electrodynamics, 2018, no.2, pp. 3-10. (Rus). doi: 10.15407/techned2018.02.003. 9. Kim J.-S., Rim G.-H., Jin Y.-S., Lee H.-S., Suk H.-Y., Kim K.-S., Jung J.-W., Sung G.-Y. A flexible control scheme for current wave forming using multiple capacitor bank units. PPPS-2001 Pulsed Power Plasma Science 2001. 28th IEEE International Conference on Plasma Science and 13th IEEE International Pulsed Power Conference. Digest of Papers (Cat. No.01CH37251). doi:10.1109/ppps.2001.1001846.

10. Suprunovska, N.I.; Shcherba, A.A. Features of the energy interchange between capacitors in the circuit using unidirectional commutator or bidirectional one. Proceedings IEEE International Conference on Intelligent Energy and Power Systems (IEPS-2016), June 7-11, 2016, Kyiv, Ukraine, pp. 6-10. doi: 10.1109/IEPS.2016.7521843.

Received 22.05.2018

N.I. Suprunovska ${ }^{1}$, Doctor of Technical Science,

M.A. Shcherba ${ }^{1}$, Candidate of Technical Science,

${ }^{1}$ The Institute of Electrodynamics of the NAS of Ukraine, 56, prospekt Peremogy, Kiev, 03057, Ukraine, phone +380443662493 ,

e-mail: iednat1@gmail.com, m.shcherba@gmail.com 